\title{
Echo-Mammographic and Anatomo-Pathological Aspects of Male Breast Cancer in Togo
}

\author{
Bidamin N'timon ${ }^{1 *}$, Tchin Darré2, Massaga Dagbé1, Pihou Gbandé3, Abdoulatif Amadou4, \\ Mazamaesso Tchaou ${ }^{3}$, Lantam Sonhaye ${ }^{4}$, Samadou Aboubakari ${ }^{5}$, Kodzo Selom Edi ${ }^{3}$, \\ Lama Kègdigoma Agoda-Koussema3 ${ }^{3}$, Komlavi Adjenou ${ }^{4}$
}

\author{
${ }^{1}$ Department of Radiology, University Teaching Hospital of Kara, Kara, Togo \\ ${ }^{2}$ Department of Pathology, Sylvanus Olympio University Teaching Hospital of Lomé, Lomé, Togo \\ ${ }^{3}$ Department of Radiology, Sylvanus Olympio University Teaching Hospital of Lomé, Lomé, Togo \\ ${ }^{4}$ Department of Radiology, Campus University Teaching Hospital of Lomé, Lomé, Togo \\ ${ }^{5}$ Department of Obstetrics and Gynecology, University Teaching Hospital of Kara, Kara, Togo \\ Email: *cntimon@yahoo.fr
}

How to cite this paper: N'timon, B. Darré, T., Dagbé, M., Gbandé, P., Amadou, A., Tchaou, M., Sonhaye, L., Aboubakari, S., Edi, K.S., Agoda-Koussema, L.K. and Adjenou, K. (2017) Echo-Mammographic and Anatomo-Pathological Aspects of Male Breast Cancer in Togo. Open Journal of Radiology, 7, 250-258.

https://doi.org/10.4236/ojrad.2017.74028

Received: October 24, 2017

Accepted: December 8, 2017

Published: December 11, 2017

Copyright $\odot 2017$ by authors and Scientific Research Publishing Inc. This work is licensed under the Creative Commons Attribution International License (CC BY 4.0).

http://creativecommons.org/licenses/by/4.0/

\section{c) (i) Open Access}

\begin{abstract}
Studies of male breast cancer are rare in Africa. In Togo in particular, no work has focused on the epidemiological, mammo-echographic, pathological, therapeutic or prognostic aspects of male breast cancer. The aim of this study is to report cases of male breast cancer in Togo by describing the main epidemiological, mammo-echographic and pathological aspects. This was a retrospective, descriptive and analytical study of 10 cases of male patients presenting with breast cancer confirmed by the pathologic examination on the echoguided samples over a period of 6 years in University Teaching Hospital in Lomé. A total of ten patients were retained. The mean age of patients was 55 years with extremes of 39 years and 65 years. All patients had a palpable breast mass. The lesions were classified in 60\% American College of Radiology (ACR) 5 and $40 \%$ ACR 4 . The axillary lymph node invasion rate was $40 \%$. Infiltrating ductal carcinoma was the histologic type diagnosed in all patients. Any breast mass in an elderly male subject is suspected with high predictive value. Mammography ultrasound plays an important role in the diagnosis alongside pathology.
\end{abstract}

\section{Keywords}

Male, Breast, Cancer, Mammography-Ultrasound, Pathology, Togo

\section{Introduction}

Breast cancer, the first malignant disease in women, remains a rare disease in 
men, accounting for less than $1 \%$ of breast cancers and less than $1 \%$ of all male neoplasias [1]. There are 2000 new cases of male breast cancer diagnosed each year in the United States in a recent study published in May 2017 [2]. In Africa where it was long ignored, male breast cancer, is characterized by a late diagnosis [3]. Recent studies in Morocco and Nigeria has shown that the disease is present in Africa as well as in developed countries because of longer life expectancy and better accessibility to screening and treatment facilities. This disease was very deadly in Africa [4] [5]. The diagnosis is radiological (ultrasound and mammography or MRI) and anatomo-pathological. The treatment includes alone or in combination, chemotherapy, radiotherapy, surgery and hormone therapy depending on the stage of the disease and the immunohistochemical type.

In Togo, no work has focused on the epidemiological, mammo-echographic and pathological aspects of breast cancer in humans because of the lack of knowledge of this pathology in the population and the lack of diagnostic infrastructures for many years. Currently, with the popularization of mammography, ultrasound and pathology examinations, as well as the availability of competent medical personnel especially in Lome, the disease is increasingly diagnosed. In this new context, our study is designed to describe the epidemiological, mammographic and anatomopathological aspects of these cancers.

\section{Patients and Methods}

It was a retrospective, descriptive and analytical study on the files of patients existing in the Imaging and Anatomy-pathology departments of University Teaching Hospital of Lomé (Togo). It took place from October 1, 2009 to September 30, 2015, a period of six (06). Male patients referred for suspected cancer in whom breast ultrasound and mammography were performed. The echo-guided biopsies were performed in his patients with histological confirmation of cancer. The breasts as well as the axillary regions were explored in search of adenomegaly. It was considered adenomegaly if a ganglionic nodule with a diameter greater than one $(01) \mathrm{cm}$ in the anteroposterior direction was detected. All lesions were classified in imaging according to the American College of Radiology (ACR). Histopathological examination made it possible to study the histological type and the histopronotic grade of Scarff Bloom Richardson (SBR). Clinical parameters (age, history and physical examination of the breast and axillaries) were also studied.

\subsection{Statistical Analysis}

Statistical processing and analysis of data was performed using SPSS software.

\subsection{Ethical Consideration}

This study received approval from the Head of the Radiology department to be conducted. Since it was counting records, patient consent was not required. However during the counting and data collection patient names were not collected in order to preserve confidentiality. 


\section{Results}

Ten patients with confirmed histologic breast cancer were recorded. The average age of patients was 55 years with extremes of 39 years and 65 years. Seven out of ten patients were over 50 years of age. Three patients had a personal history: chronic alcoholism for one patient, chronic alcoholism associated with chronic smoking in the second patient and obesity in the third patient. The delay between the beginning of clinical signs and the first consultation was 15 months. All patients had a palpable mass, one of which was associated with nipple retraction. Clinically palpable axillary adenomas were observed on the homolateral side of the mammary mass in $40 \%$ of the cases. All the masses were tissue on ultrasound (Figure 1). The results of mammography (Figure 2) and ultrasound are summarized in Table 1 and Table 2, respectively.

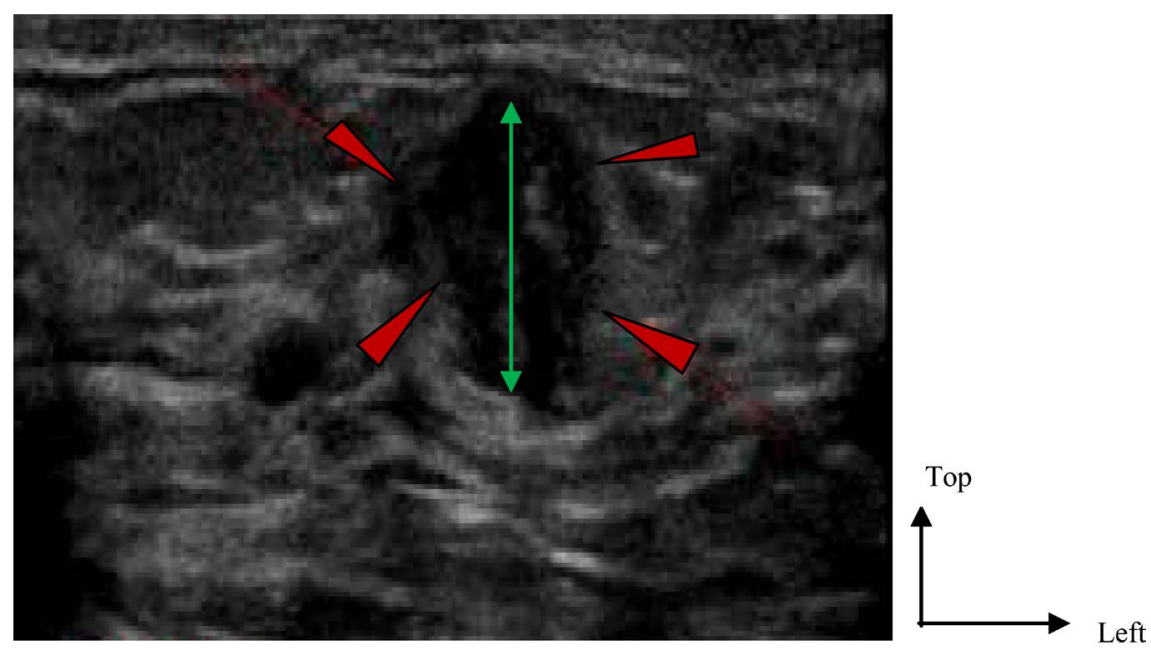

Figure 1. Irregular hypoechoic mass (red arrow head) with long vertical axis (green line).
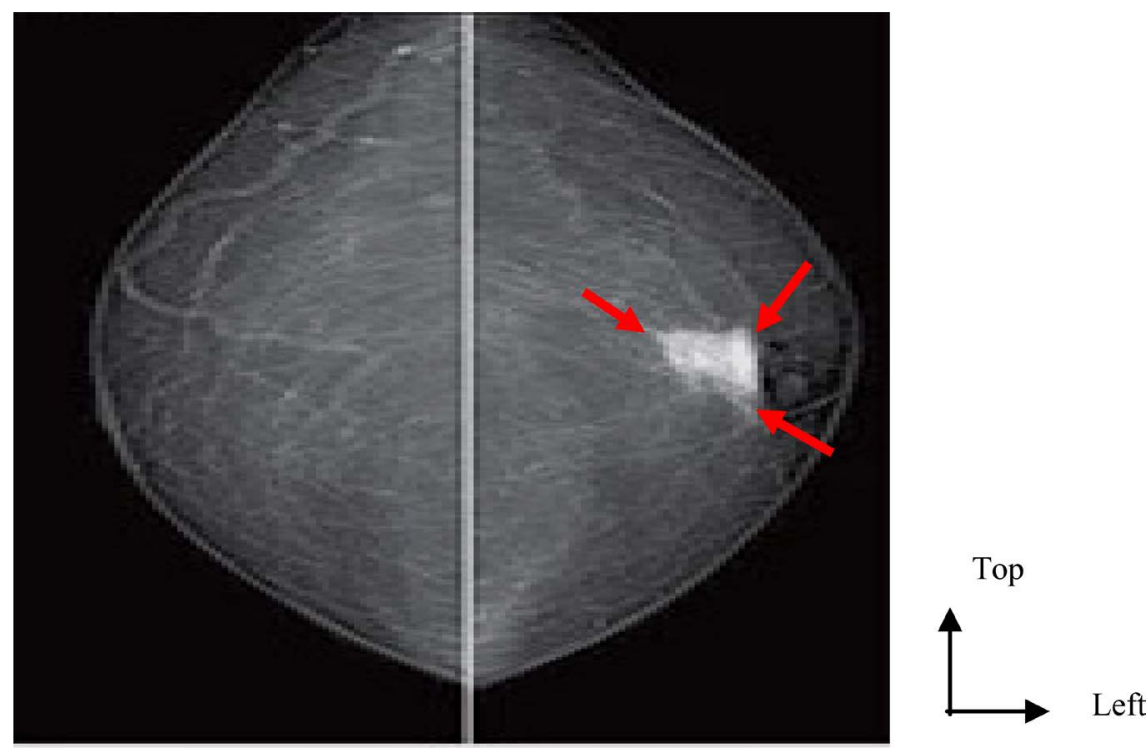

Figure 2. Mammography face impacts: high-density opacity with irregular contours (Red arrow) of retroareolar left breast. 
Table 1. Mammographic characteristics of lesions according to patients.

\begin{tabular}{|c|c|c|c|c|c|c|}
\hline & & ography & Density of opacity & Contours & Microcalcifications & Classification $\mathrm{ACR}^{* * * *}$ \\
\hline 1 & Law & Retroareolar & Strong & Not Specified & Absents & ACR5 \\
\hline 2 & Left & $\mathrm{QSE}^{*}$ & Average & Limited & Yes & ACR4 \\
\hline 3 & Law & Retroareolar & Average & Irregular & Yes & ACR4 \\
\hline 4 & Left & Retroareolar & Strong & Irregular & No & ACR4 \\
\hline 5 & Left & $\mathrm{QIE}^{* *}$ & Average & Irregular & No & ACR4 \\
\hline 6 & Left & Retroareolar & Strong & Irregular & Yes & ACR5 \\
\hline 7 & Left & Retroareolar & Average & Spiculated & Yes & ACR4 \\
\hline 8 & Left & QSE & Strong & Spiculated & No & ACR5 \\
\hline 9 & Left & Union of QI*** & Strong & Irregular & Yes & ACR5 \\
\hline 10 & Law & Retroareolar & Strong & Irregular & No & ACR5 \\
\hline
\end{tabular}

${ }^{\star}$ Supper-External Quadrant; ${ }^{* *}$ Inferior-External Quadrant; ${ }^{* *}$ Lower Quadrant; ${ }^{* * * *}$ American College of Radiology.

Table 2. Ultrasound characteristics of mammary masses according to patients.

\begin{tabular}{|c|c|c|c|c|c|c|c|}
\hline & $\begin{array}{c}\text { Topography } \\
\text { (Quadrant/ breast }\end{array}$ & $\begin{array}{c}\text { Dimensions } \\
(\mathrm{D} 1 \times \mathrm{D} 2 \text { in } \mathrm{mm})\end{array}$ & Echogenicity & Contours & Large Axis & $\begin{array}{l}\text { Lateral } \\
\text { attenuation }\end{array}$ & $\begin{array}{c}\text { Ipsilateral } \\
\text { adenomegalies }\end{array}$ \\
\hline 1 & All right breast & $50 \times 42$ & Heterogeneous & $\mathrm{IR}^{\#}$ & No & Yes & Yes \\
\hline 2 & $\mathrm{QSE}^{\star} / \mathrm{Left}$ & $35 \times 33$ & Heterogeneous & IR & No & No & Yes \\
\hline 3 & Retroareolalar/right & $32 \times 26$ & Hypoechoic & IR & No & Yes & No \\
\hline 4 & Retroareolar/left & $40 \times 30$ & Hypoechoic & IR & No & No & No \\
\hline 5 & $\mathrm{QIE}^{\star *} / \mathrm{left}$ & $28 \times 25$ & Hypoechoic & IR & Yes & Yes & Yes \\
\hline 6 & Retroareolar/left & $33 \times 25$ & Hypoechoic & fuzzy & Yes & Yes & No \\
\hline 7 & Retroareolar/left & $27 \times 20$ & Hypoechoic & IR & Yes & Yes & No \\
\hline 8 & QSE/left & $32 \times 28$ & Hypoechoic & IR & No & Yes & No \\
\hline 9 & Union of $\mathrm{QI}^{* * *} / \mathrm{left}$ & $26 \times 28$ & Hypoechoic & IR & Yes & No & Yes \\
\hline 10 & QIE/right & $15 \times 16$ & Hypoechoic & IR & Yes & No & No \\
\hline
\end{tabular}

*Supper-External Quadrant; **Inferior-External Quadrant; ${ }^{* * *}$ Lower Quadrant; *irregular.

The macroscopic aspects were in $40 \%$ encephaloid forms, $30 \%$ squirrheous forms, $20 \%$ forms of ulcerous tumors buds and $10 \%$ nodular form in the form of a "bean". Histological, infiltrating ductal carcinoma (Figure 3) was found in all patients with histoprotic SBR respectively $60 \%$ grade II, $30 \%$ grade I and $10 \%$ grade III.

\section{Discussion}

We carried out a retrospective and descriptive study that examined the analysis of breast cancer cases in humans with data collected in radiochemical and pathological observations of 10 patients with mammary masses. On the basis of mammo-ultrasound data. These were most likely suspicious lesions classified as 


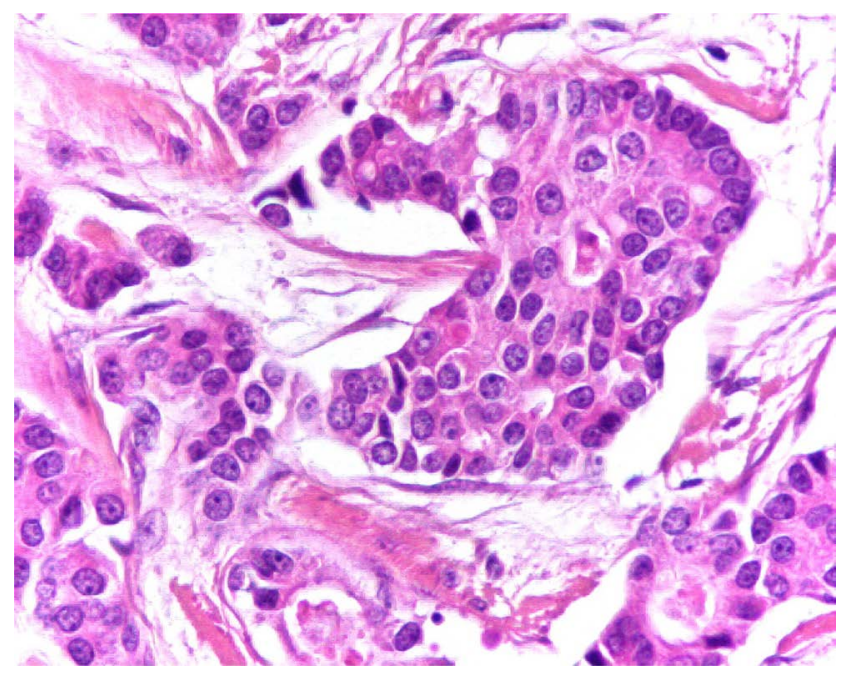

Figure 3. Infiltrating ductal carcinoma SBR 2 (HE, 40×) (Source Laboratory of Pathological Anatomy).

ACR4 or malignant lesions classified as ACR5. The pathological examination made it possible to establish the diagnosis of ductal carcinoma infiltrating the breast.

This study has the merit of making for the first time in our country an update on breast cancers in humans concerning the echo-mammographic aspect and only concerned the University Teaching Hospital in Lomé. It could have spread to all the health centers of the country in order to have a real approach on this pathology in Togo. Epidemiologically, all studies have produced the same agerelated findings for patients with breast cancer that predominantly occur in relatively elderly patients [6] [7]. This observation is valid in our study where the mean age is 55 years. According to the American Cancer Society, this average age varies between 60 and 65 years [8]. This average age is 61 years old in a Moroccan study [4]. The data regarding Risk factors for male breast cancer are known but rare and in our study these factors are found in 30\% of our patients. These include chronic alcoholism, obesity and chronic smoking. Concerning obesity and in a recent study in israel, it is proved that adolescent overweight and obesity are associated with increased risk of mal breast cancer, suggesting a modifiable risk factor potentially allowing for early intervention [9].

Radiological, the diagnosis is based on ultrasound and mammography. Predictive signs of malignancy are well defined. These signs are increasingly detected with the evolution of the technology allowing the use of increasing frequency probes allowing diagnosis in sub-clinical stages [10] [11]. These signs are represented by hypoechogenicity, the irregular appearance of the contours, the attenuation of the posterior beam, the major vertical axis and the micro calcifications. Hypoechogenicity has a high predictive value. In the study of Starvorselle, it is $92 \%$ [12] and in our study its predictive value of malignancy is $64 \%$. Irregular micro-lobulated or angular appearance is a feature of malignancy. It is present in $60 \%$ in our series and $88.6 \%$ in that of Starvors et al. [12]. The attenu- 
ation of the posterior beam varies according to the cancer reaction stroma. In the Stravors et al. study, this characteristic was present in $76 \%$ of cases, mainly in tubular cancers, with a sensitivity of $76 \%$ and specificity of $96 \%$ [13]. On the other hand, medullar cancers, haemorrhagic or necrotic forms have a normal or enhanced ultrasound beam more often [14]. In our study, this sign was found in $60 \%$ of our patients. The major vertical axis is a predictive sign of malignancy as opposed to the major transverse axis which is a sign of benignity [10] [15]. This sign is present in $30 \%$ of cases in our series. Isolated or focal micro calcifications when seen on ultrasound are observed in malignant lesions [16] [17]. In our study we identified $50 \%$ of this sign. Other signs of malignancy are skin thickening and axillaries adenomegia found in $40 \%$ of our patients. At mammography, the morphology of the contours of the lesions, their density and the characteristics of the micro calcifications are the semiological elements analyzed. Concerning the morphology of the contours, the irregular contours in their speculated form are characteristics of the mainly infiltrating cancers [18]. In our study $20 \%$ of this form was identified. As for micro calcifications, their diagnosis is more the responsibility of the mammography with sensitivity and a specificity of $93 \%$ and $55 \%$ respectively for the field mammograms against $89 \%$ and $45 \%$ for the conventional mammography [19]. The analysis of these micro calcifications in the BIRADS system is based mainly on their morphology, number and distribution. In our study, the irregular type, polymorphic and grouped in clusters was found in 50\%. In our series, breast cancers were mostly located on the left in $70 \%$ of cases compared to $30 \%$ on the right. This lack of symmetry is found in several studies [6] [20]. No hypothesis is put forward to explain this left predominance in our study since both breasts are histological identical. Other studies have shown that tumors reach both breasts without any difference [21].

From an anatomopathological point of view and on a macroscopic level, the predominance of the ulcer cumulative form was found [22] whereas it represented only $20 \%$ in our study. The immunohistochemical study was not done because of the inadequacy of the equipment. Microscopic examination found $100 \%$ of infiltrating ductal carcinoma. This net prevalence has been unanimously confirmed in other studies [22] [23] [24]. The histoprotic grade of SBR studied in this series revealed the predominance of grade II on the order of $60 \%$. The same predominance is found in other studies whereas a predominance of group III has been found in other studies [25] [26]. This predominance of infiltrating carcinomas makes it possible to say that male breast cancer is very often diagnosed invasively in both developing and developed countries [27] [28] despite the existence of more efficient structures in these countries. Women are almost the only beneficiaries of the performance of these early diagnosis facilities, since the diagnosis of breast cancer is a common and almost systematic practice. The delay in the diagnosis of male breast cancer, even in developed countries, is also related to the lack of attention that men generally give to their breasts compared to women and the lack of awareness of the disease both by patients themselves than 
by some health personnel. In addition, studies in the United States have shown that in the diagnosis of mammary cancer, black men report to the hospital later than whites [29].

\section{Conclusion}

The breast cancer in humans in Togo is found in the relatively old subject in our series as in most studies. The mammo-ultrasound pair represents the basic examination which makes it possible to do most of the diagnosis to the imaging by showing malignant or suspicious lesions of malignancy. The histological examination after biopsy resection found the ductal carcinoma infiltrating in all our patients. Knowledge of the condition and the radiographic aspect by sinologists appears essential for the diagnosis to the imagery.

\section{Conflicts of Interest}

The authors report no conflict of interest.

\section{Authors Contributions}

BN was responsible for the design of the study, undertook the field study, performed data collection, analysis and interpretation, and wrote the manuscript. TD, MD, PG, AA, TM, LS, SA, SKE AND KA: participated in the design of the study, supervised the data collection and participated in the data analysis. LKAK is responsible for the overall scientific management of the study, the analysis and interpretation, and preparation of the final manuscript. All authors have read and approved the final manuscript to be submitted for publication.

\section{References}

[1] Tunon de Lara, C., Goudy, G., MacGrogan, G., Durand, M., Dilhuydy, J.M., Avril, A., et al. (2008) Breast Cancer in Men: About 52 Cases Managed at the Bergonié Institute of Bordeaux between 1980 and 2004. Gynécologie Obstétrique \& Fertilité, 36, 386-394. https://doi.org/10.1016/j.gyobfe.2008.02.020

[2] Javidiparsijani, S., Rosen, L.E. and Gattuso, P. (2017) Male Breast Carcinoma: A Clinical and Pathological Review. International Journal of Surgical Pathology, 25, 200-205. https://doi.org/10.1177/1066896916675953

[3] Ndom, P., Um, G., Bell, E.M., Eloundou, A., Hossain, N.M. and Huo, D. (2012) A Meta-Analysis of Male Breast Cancer in Africa. Breast, 21, 237-241. https://doi.org/10.1016/j.breast.2012.01.004

[4] Alaoui Slimani, K., Debbagh, A., Sbitti, Y., Errihani, H. and Ichou, M. (2016) Male Breast Cancer in Morocco: Epidemiology and Prognostic Factors. A Report of 140 Cases. Gynécologie Obstétrique \& Fertilité, 44, 636-640. https://doi.org/10.1016/j.gyobfe.2016.08.009

[5] Olu-Eddo, A.N. and Momoh, M.I. (2010) Clinicopathological Study of Male Breast Cancer in Nigerians and a Review of the Literature. Nigerian Quarterly Journal of Hospital Medicine, 20, 121-124.

[6] Heller, K.S., Rosen, P.P., Schottenfeld, D., Ashikari, R. and Kinne, D.W. (1978) Male Breast Cancer: A Clinico Pathology Study of 97 Cases. Annals of Surgery, 188, 
60-65. https://doi.org/10.1097/00000658-197807000-00010

[7] Chevalier, B. and Bastit, P. (1981) Male Breast Cancer. La Nouvelle Presse Medicale, 10, 901-904.

[8] George, H. and Perkins (2003) Breast Cancer in Men. Treatment Is Based on Results Extrapolated from Trials for Women with Breast Cancer. BMJ, 327, 239-240.

[9] Keinan-Boker, L., Levine, H., Leiba, A., Derazne, E. and Kark, J.D. (2017) Adolescent Obesity and Adult Male Breast Cancer in a Cohort of 1,382,093 Men. International Journal of Cancer, 21. https://doi.org/10.1002/ijc.31121

[10] Blohmer, J.U., Schmalisch, G., Kurten, A., Chaoui, R. and Lichtenegger, W. (1997) Revelance of Sonographic Criteria for Differential Daignosis of Mammary Tumours. European Journal of Ultrasound, 6, 35-41. https://doi.org/10.1016/S0929-8266(97)00035-9

[11] David, P. (2004) Valeur primordial de l'échographie en aval de la mammographie de dépistage du cancer du sein. Le Sein, 14, 2-18.

[12] Stravors, T., Thickman, D. and Rapp, C.L. (1995) Solid Breast Nodules: Use of Sonography to Distinguish between Benign and Malignant Lesions. Radiology, 196, 123-134. https://doi.org/10.1148/radiology.196.1.7784555

[13] Chao, T.C., Lo, Y.F., Chen, S.C. and Chen, M.F. (1999) Prospective Sonographic Study of 3093 Breast Tumors. Journal of Ultrasound in Medicine, 18, 363-370. https://doi.org/10.7863/jum.1999.18.5.363

[14] Fornage, B.D., Lorigan, J.G. and Andry, E. (1989) Fibroadenoma of the Breast: Sonography Appearance. Radiology, 172, 671-675.

https://doi.org/10.1148/radiology.172.3.2549564

[15] Richter, K. and Heywang-Kobruner, S.H. (1995) Quantitative Parameters Measured by a New Sonographic Method for Differentiation of Benign and Malignant Breast Disease. Investigative Radiology, 30, 401-411. https://doi.org/10.1097/00004424-199507000-00003

[16] Mesurolle, B., El-Khoury, M., Hori, D., Phancao, J.P., Kary, S., Kao, E. and Fleiszer, D. (2006) Sonography of Postexcision Specimens of Nonpalpable Breast Lesions: Value, Limitations, and Description of a Method. American Journal of Roentgenology, 186, 1014-1024. https://doi.org/10.2214/AJR.05.0002

[17] Isabelle, L. (2006) Quelle est la place de l'échographie dans le dépistage du cancer du sein? Le Sein, 16, 95-100.

[18] Tardivon, A., Guinebretiere, J.M. and Dromain, C. (2002) Radiologic-Pathologic Correlations in Breast Diseases. Journal of Radiology, 83, 555-563.

[19] Seror, J.Y., Sheuer-Niro, B., Ghenassia-Vidal, C. and Scetbon, F. (2004) Les Microcalcifications Mammaires: De l'image à la biopsie. JTA, 1, 1-15.

[20] Arfaoui, A., Daagare, A. and Ayoujil, A. (2007) Épidémiologie des cancers au Maroc. Étude sur l'échantillon: Centre d'oncologie Al Azhar de Rabat. Onconews, 26, 35-39.

[21] Bernheim, J., Griffel, B. and Chen, V. (1985) Cancer of the Breast in Men in Israël. Archives D'Anatomie Et De Cytologie Pathologiques, 33, 268-272.

[22] Daman, S. and Blamy, D. (1997) Cancer du sein de l'homme en milieu africain. A propos de 5 cas observés au CHU de Ouagadougou (Burkina Faso). Bulletin du Cancer, 2, 175-177.

[23] Berrada, S., Essadki, B., Aboulhassan, K. and Zerouali, N.O. (1992) Le cancer du sein chez l'homme à propos de 26 cas. Médecine du Maghreb, 33, 9-10.

[24] Meynard, P., Jacquemier, J., Hans, D., Ayme, Y., Varette, Y., Spitalier, J.M., et al. 
(1989) Clinically Impalpable Mammary Carcinoma: Morphologic and Histogenetic Analysis. Apropos of 114 Cases. Bulletin du Cancer, 76, 653-661.

[25] Darré, T., Amegbor, K., Sonhaye, L., Kouyaté. M., Aboubakari, A., N’Timon, B., et al. (2013) Profil histo-épidémiologique des cancers du sein: A propos de 450 cas observes au CHU de Lomé. Médecine d Afrique Noire, 60, 54-58.

[26] Essiben, F., Foumane, P., Mboudou, E.T., Dohbit, J.S., Mvekoh, V. and Ndom, P. (2013) Diagnostic et traitement du cancer de sein au cameroun: A propos de 65 cas. Mali Médical, 28, 1-5.

[27] Giordano, S.H., Buzdar, A.U. and Hortbagyi, N. (2002) Breast Cancer in Men. Annals of Internal Medicine, 137, 678-687. https://doi.org/10.7326/0003-4819-137-8-200210150-00013

[28] Andre, S., Fonseca, I., Pinto, A.E., Cardoso, P., Pereira, T. and Soeres, J. (2001) Male Breast Cancer-A Reappraisal of Clinical and Biologic Indicators of Prognosis. Acta Oncologica, 40, 472-478. https://doi.org/10.1080/028418601750288190

[29] O’Malley, C.D., Prehn, A.W., Shema, S.J. and Glaser, S.L. (2002) Racial/Ethnic Differences in Survival Rates in a Population-Based Series of Men with Breast Carcinoma. Cancer, 94, 2836-2843. https://doi.org/10.1002/cncr.10521 